\title{
Students' Involvement in Authentic Modelling Practices as Contexts in Chemistry Education
}

\author{
Gjalt T. Prins • Astrid M. W. Bulte • Jan H. Van Driel • \\ Albert Pilot
}

Published online: 17 September 2008

(C) The Author(s) 2008. This article is published with open access at Springerlink.com

\begin{abstract}
In science education students should come to understand the nature and significance of models. A promising strategy to achieve this goal is using authentic modelling practices as contexts for meaningful learning of models and modelling. An authentic practice is defined as professionals working with common motives and purposes, pertaining to a similar type of procedure and applying relevant knowledge on the modelling issue they work on. In this study we evaluate whether the use of authentic practices initiates adequate students' involvement. This was done by investigating students' interests, ownership, familiarity and complexity. In addition, we evaluated students' expressed modelling procedures in response to the modelling issues. We designed learning tasks which were enacted by a focus group of students. Three primary data sources were used to collect data. Firstly, a group discussion was organised in which students' reflected on both authentic practices. Secondly, students filled in written questionnaires containing items on affective and cognitive aspects. Thirdly, the realised modelling procedures by students were analysed. The results show that students' involvement was successfully initiated, evidenced by motivated students, willingness to continue and the completeness and quality of the realised modelling procedures. The design of the learning tasks proved to be successful in realising this involvement. The results obtained in this study support the strategy of using authentic modelling practices as contexts for meaningful learning of models and modelling.
\end{abstract}

Keywords Chemistry education $\cdot$ Modelling $\cdot$ Context $\cdot$ Authentic practices · Students' involvement

G. T. Prins $\cdot$ A. M. W. Bulte $\cdot$ A. Pilot

Freudenthal Institute for Science and Mathematics Education, Utrecht University, Utrecht, The Netherlands

J. H. Van Driel

ICLON Leiden University Graduate School of Teaching, Leiden University, Leiden, The Netherlands

Present address:

G. T. Prins $(\bowtie)$

Princetonplein 5, 3584 CC Utrecht (De Uithof), The Netherlands

e-mail: g.t.prins@phys.uu.nl 


\section{Introduction}

Models are essential both in science and in science education. As such, models are generally viewed as connections between the scientific theory and the world as experienced. Currently, the learning of models and modelling is regarded as an integral part of scientific literacy (Clement 2000; Gilbert 2004). Given the fact that modelling is considered an essential element of scientific thinking, there is an urge to design learning environments such that students' understanding of the nature of models is enhanced (Harrison and Treagust 1998).

In science education, the terms model and modelling are used quite ambiguously (Harrison and Treagust 2000). Examples of models used are iconic and symbolic models, to depict chemical formulae and chemical equations, mathematical models to represent conceptual relationships of physical properties and processes (e.g. PV $=n R T)$ and theoretical models to describe well-grounded theoretical entities (e.g. kinetic theory model of gas volume, temperature and pressure). In this paper we concentrate on models and modelling in chemistry education. We use the term model as some structured representation, including symbolic elements, of the essential characteristics of an idea, object, event, process or system (Gilbert and Boulter 2000). In addition, we define the act of modelling as the construction, evaluation and revision of a model in response to a particular task (Van der Valk et al. 2007).

Many studies have revealed that students do not effectively learn about models and modelling (Grosslight et al. 1991; Harrison and Treagust 1996) Students, in general, think of models as copies of reality. Students have problems capturing more advanced features of model understanding, like the purpose of creating models, models as representations of ideas in contrast to reality, the construction of models and the notion that models can be tested and changed in order to inform the development of ideas. There is substantial evidence that the traditional chemistry curriculum does not fully support students' learning of models and modelling. Erduran and Duschl (2004) pointed out some trends within the traditional framework of chemistry teaching that account for this lack of support. Firstly, chemical models are presented to students as final versions of our knowledge, neglecting the tentative nature of models. Secondly, textbooks often present inaccurate 'hybrid' models which cause confusion among students (Carr 1984). Thirdly, chemical models have been synonymised with the visual ball-and-stick models, resulting in a unilateral view on chemical models from a student's perspective. Finally, chemical experimentation has rarely been implemented as an activity through which models are developed, evaluated and revised. Given these trends how models and modelling are implemented in chemistry education, the motivations, strategies and arguments underlying the development, evaluation and revision of chemical models are overlooked. To overcome these problems, the trajectory of learning of models and modelling needs to be redefined.

Students should become actively involved in modelling processes in which they develop understanding of their models including the evaluation and testing (Penner et al. 1998; Raghavan and Glaser 1995). It has been claimed that this aspiration might be realised by designing a learning environment which accurately reflects an authentic science practice that employs models (Edelson 1998; Roth 1998). Students need to experience models in processes similar as those used in research laboratories or other settings in which real science takes place (Sadler 2007).

As appealing the benefits might be, the empirical basis supporting these theoretical claims is limited. In addition, the design knowledge for adapting the characteristic features of authentic practices into contexts for curriculum units is inadequate. Therefore, as part of a larger research project, this study evaluated whether the use of authentic practices as contexts initiates adequate students' involvement for learning models and modelling. For this we designed learning tasks which were enacted by a focus group of students. 


\section{Theoretical Framework}

Coherency between modelling activities and issue knowledge can be achieved by defining context as a cultural entity in society (Bulte et al. 2005; Gilbert 2006; Sadler 2007). Following this proposition, we use authentic chemical practices as contexts for curriculum units (Bulte et al. 2006). We define an authentic practice as a homogeneous group of people in society working on real-world problems and issues in a 'community' connected by three characteristic features: common motives and purposes, working according to a similar type of characteristic procedure leading to an outcome and using relevant knowledge about the issue they work on (Westbroek 2005). The use of authentic practices as contexts relate to the activity theory in education, rooted in the socio cultural tradition (Leont'ev 1978; Vygotsky 1978).

However, when using authentic practices as contexts for curriculum units, one needs to acknowledge significant differences between the population of students and that of experts. Any adaptation of an authentic practice will need to address three primary aspects: curriculum structure; teacher preparation; and learner-appropriate resources, such as attitudes, tools and techniques (Edelson 1998). In this study we focus specifically on the students' involvement. Students' involvement should be initiated at the start of the curriculum unit, in which students orient themselves with the authentic practice at hand. The issues should appeal to students, evoke their interest, encourage willingness to work and build on pre-knowledge and intuitive notions. For establishing adequate involvement of students, three conditions should be satisfied to a sufficient extent. Below each condition is addressed briefly.

\section{Condition A. Connect to Students' Interest and Ownership}

We agree with Bennett and Holman (Bennett and Holman 2002) that the use of recognisable contexts in science education potentially fosters students' interest and ownership. By means of such a context students are expected to become active learners, they are expected to acquire scientific knowledge in a meaningful context and to develop appropriate styles of inquiry and communication. However, experts do have different interests and sense of ownership compared to students. So, the authentic practice as context should evoke students' interest and initiate ownership in order to achieve adequate involvement.

\section{Condition B: Comply with Students' Familiarity and Complexity}

Experts have a vast amount of knowledge about an issue. This knowledge covers, amongst other things, the scientific concepts, tools and techniques. We need to account for differences in knowledge between experts and students. The extent to which students are able to cope with the cognitive load of an issue depends primarily on the familiarity with the issue and perceived complexity (Taconis et al. 2001). In conclusion, the modelling issue addressed should be sufficiently familiar to students with manageable complexity.

\section{Condition C. Build on Students' Procedural Modelling Knowledge}

In the past decade considerable interest has developed in the design of modelling processes at all levels of schooling in science education (Clement 2000; Hodgson 1995; Ingham and Gilbert 1991; Raghavan and Glaser 1995). A common goal of the numerous approaches is to engage learners in modelling processes (Linn et al. 1991). However, modelling is a difficult enterprise for students to be engaged in and involves complex thinking. Students frequently tackle a complex issue in a fragmented, uncoordinated way or struggle to 
complete the task (Hogan and Thomas 2001; Riley 1990). Various studies have been carried out that have investigated conceptualizing modelling processes (Buckley 2000; Webb 1994). The study by Webb (Webb 1994) showed that students are able to express a modelling procedure in general terms, provided that students are familiar and knowledgeable with the issue. This finding is supported by other studies, showing that the development of modelling ability is heavily context dependent (Carey 1985). The stages in the modelling process for general application are depicted in Fig. 1.

In conclusion, in order to initiate students' involvement it is essential that the modelling issue builds on students' procedural modelling knowledge. Students should be able to express, in a rudimentary sense, a modelling procedure in response to the issue. Such a modelling procedure should consist of a series of modelling activities accompanied by relevant issue knowledge.

\section{Scope and Research Questions}

This research study is positioned within the broader perspective to develop and investigate context-based curriculum units in science education. The aim of this study was to investigate to what extent the use of authentic practices as contexts initiates adequate students' involvement for learning models and modelling. Two authentic practices were evaluated. For this we designed learning tasks which were enacted with a focus group of students'. Three research questions are addressed:

1. To what extent does the use of authentic practices as contexts evoke students' interest and initiate ownership?

2. To what extent are students familiar with the modelling issues and able to manage the complexity?

3. To what extent are students able to express a rudimentary procedure in response to modelling issues, in terms of a sequence of activities accompanied by relevant issue knowledge?

The first question elaborates condition $\mathrm{A}$, the second condition $\mathrm{B}$ and the third question condition $\mathrm{C}$.

Fig. 1 A six-stage modelling process for general application, originating from the Modus project. Bold lines indicate the direction of the process; the dotted lines represent the flow of information (Webb 1994)

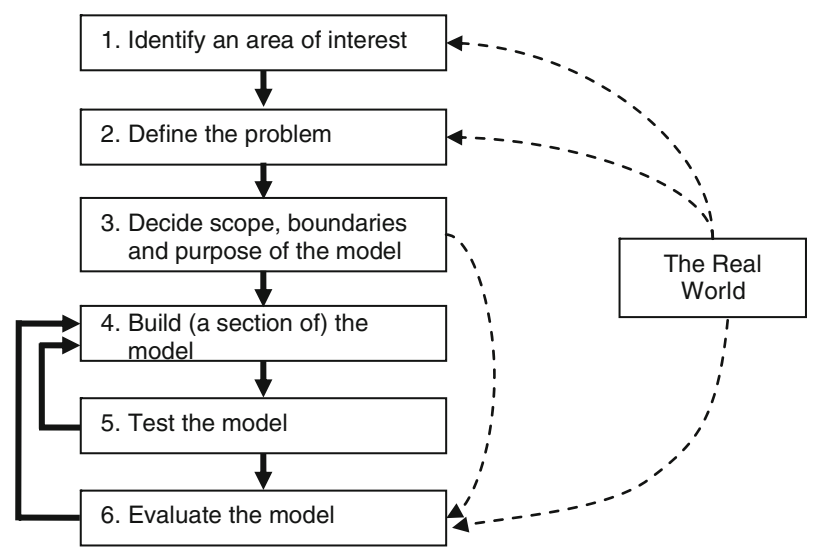




\section{Method}

In this section the participants, the authentic practices, the designed learning tasks, the enactment of the learning tasks, the data collection and analysis are described. At the end of this section an overview is given of data sources for each research question.

\section{Participants}

In total 18 grade 10-11 students from three schools in Utrecht, The Netherlands, participated, each receiving financial compensation. The cohort consisted of 12 girls and six boys. Each participant was asked to fill in a questionnaire about their view on chemistry education at school and personal reasons to participate. All students studied chemistry at high school. The majority (15) of the students appreciated chemistry. The experimental work was mentioned as the most attractive part, next to explanations of phenomena. The calculation part of chemistry was considered least interesting as well as studying topics hardly linked to the 'real world', such as balancing reaction equations. The average score of the students on chemistry was 6.5 on a scale of 1 (low) to 10 (high). The lowest score was 4.9, the highest 8.0. Chemistry was considered 'difficult' by nine students and 'easy' by the other nine students. The experienced difficulty was mainly caused by 'trouble in imagining what chemistry is about'. The main reason to participate in this study was to contribute to the development of new content for chemistry classes and orientation on possible topics for the obligatory science project each science student has to carry out for their final assessment in secondary school.

\section{Authentic Chemical Modelling Practices}

In a previous study we selected two authentic chemical modelling practices as contexts for learning of models and modelling: 'Modelling drinking water treatment' and 'Human exposure and uptake of chemicals from consumer products' (Prins et al., in press). The selection was based upon criteria: students' interest, ownership, familiarity and complexity. Both authentic modelling practices are described below.

\section{Modelling Drinking Water Treatment}

The growing water demand in The Netherlands in the past decades caused an intensified use of existing sources. This tendency resulted in a need for more detailed knowledge of the influence of various process variables on the treatment process. The aim was to develop a tool to predict the quality of drinking water depending on the quality of the raw water and treatment processes. For each treatment step, e.g. activated carbon filtration, the relevant process variables were identified. Next, their influence on the effectiveness was determined, firstly on a qualitative level using relevant chemical or biological knowledge of removal of contaminants and micro organisms, secondly on a quantitative level by gathering empirical data, through laboratory experiments and/or company data. The empirical data are analysed by statistical techniques resulting in mathematical models. For example, the developed models range from percentageremoval models, like conc $_{\text {out }}=\left(1-\frac{X}{100}\right)$ conc $_{\text {in }}$ in which $X$ is the empirically determined removal percentage, to process models that incorporate the influence of process variables, like $\mathrm{TOC}_{\mathrm{out}}=$ const $* \mathrm{TOC}_{\mathrm{in}}^{a} * \operatorname{dose}^{b} * \mathrm{pH}^{c}$ for predicting the 'total organic carbon' (TOC) removal from raw water during coagulation/flocculation treatment (const, $a, b$ and $c$ are 
empirical determined fit parameters). Each model is accompanied with a 'goodness of fit' indication and a reliability check. The complete treatment process has thus been represented by a series of mathematical models, each representative for one treatment step. Combining the models enables prediction of the quality of drinking water after treatment given a certain raw water quality.

\section{Human Exposure and Uptake of Chemicals from Consumer Products}

Consumer products comprise a large diversity, ranging from shoe polish to detergents and pesticides. All these products may contain hazardous chemicals. When a product is encountered with questionable health risks, an objective quantitative risk assessment is needed. For such assessment one needs to calculate the total uptake of potential hazardous chemicals from consumer products, based on detailed information on the composition of the product itself and on the contact route. For example, for contact route 'mouth' several physical models are available, like single ingestion $E=\frac{w_{f} q}{D V_{\text {product }}}$ and leaching from product $E(t)=E_{0} \exp ^{-\left(\frac{R A}{E_{0} V^{t}}\right)}$. In these models $E$ is the amount of compound taken up. Both models contain empirical parameters, like the initial leaching rate $(R)$, parameters specific for the product at hand, such as the initial amount of compound $\left(E_{0}\right)$, weight fraction $\left(w_{f}\right)$, surface $(A)$ and volume $(V)$, and parameters related to type of use, like amount of product $(q)$, dilution $(D)$ and duration $(t)$. When using the proper model fit for a specific contact route, one can predict the total amount of hazardous chemicals released and taken up by a consumer.

\section{Adaptation of the Authentic Practices into Contexts}

In this section we describe the adaptation of the selected authentic practices into contexts for chemistry curriculum units. The design of the learning tasks was informed by previous research on meaningful teaching-learning processes (Cobb et al. 2001; Klaassen and Lijnse 2004; Lijnse 1995). In the first three tasks students orientated on the practice. In the fourth and last task, students were given the open task to draw up a plan of action to solve an exemplary problem themselves. In this plan of action students express a series of modelling activities. In Fig. 2 a detailed description is given of the sequence and content of each learning task.

In the practice: 'Modelling drinking water treatment', hereafter named Treatment unit, students note those occasions when the quality norms of drinking water in the Netherlands are exceeded. Next, students study recommendations of experts to improve the treatment processes. In the subsequent tasks students zoom in on the treatment step coagulation/ flocculation of surface water. During coagulation/flocculation, suspended matter and colloid particles, causing turbidity of water, are removed together with attached contaminants. Students set up a modelling approach to develop a mathematical model predicting the removal of nickel by coagulation/flocculation as a function of process variables, initial nickel concentration, coagulant dose and the $\mathrm{pH}$.

In the practice: 'Human exposure and uptake of chemicals from consumer products', hereafter named Exposure unit, students orientated on the release and uptake of chemicals from consumer products, like phtalates from children's toys. Students take notice of advice from experts. Next, students focus on the release and uptake of dyes from kids-toys and plan a modelling approach to predict the total amount of dyes taken up. Students have to 


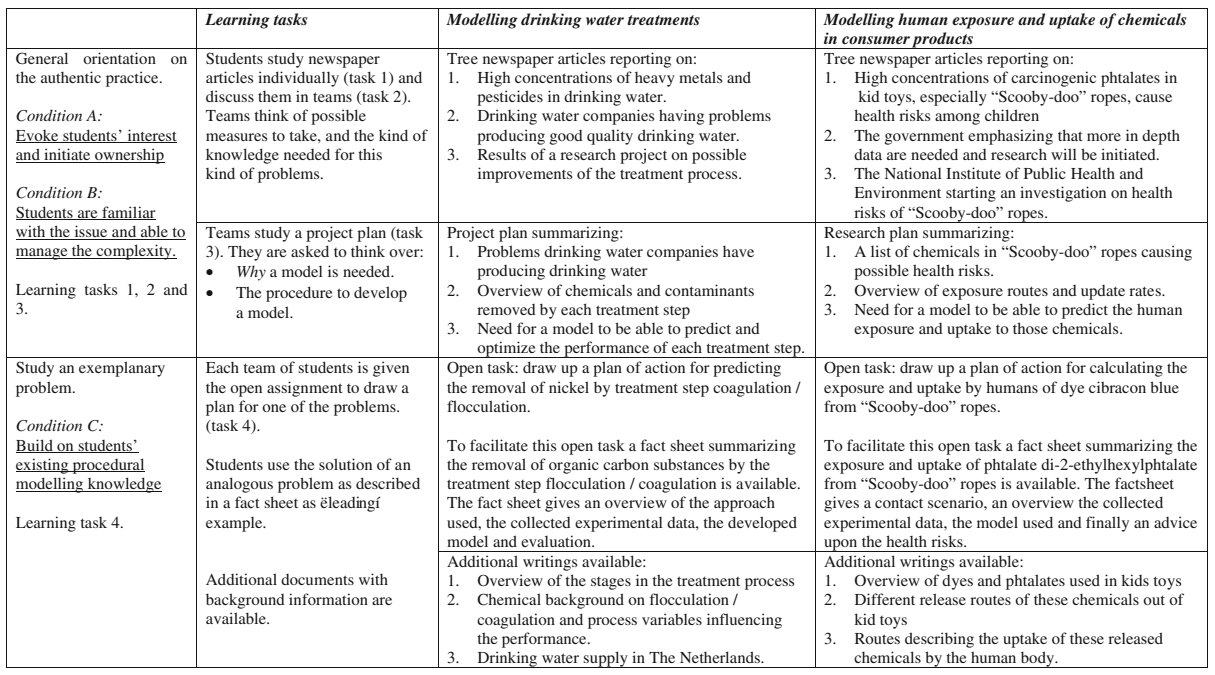

Fig. 2 Overview of the sequence and content of the learning tasks in unit Modelling drinking water treatment and unit Modelling human exposure and uptake of chemicals in consumer products

think about relevant data related to the contact route, how to collect these data and how to calculate the total amount of dye taken up with use of a proper model.

\section{Enactment of the Learning Tasks}

The enactment of the learning tasks took place in the first week of the summer holiday and consisted of four meetings of $4 \mathrm{~h}$ each. The second author of this paper was the teacher. The teacher was well acquainted with the content and the pedagogy, since she was involved in the design of the learning tasks.

The enactment started with an introductory meeting. This meeting was organised to avoid hindering effects in the second and third meetings, like students not knowing each other or students not being familiar with the type of learning activities. At the start students were grouped in six teams of three persons. Each team member was from one of the three schools and, in addition, consisted of one student with a high average score for chemistry at school, one with a medium and one with a low score. Next, the teams worked on a curriculum unit designed earlier on modelling dose-effect relationships of medicines. The type of learning tasks in this unit was similar to those in the units to be evaluated in the second and third meeting. At the end of the first meeting, students were asked to fill in a written questionnaire focusing on students' interest, ownership, familiarity with the issue and perceived complexity. The outcomes were used to evaluate the quality and to adapt the questionnaire for use in the second and third meeting.

In the second meeting the unit Treatment was enacted, and in the third the unit Exposure. In both meetings the teacher started with a short plenary introduction. Next the students worked in teams on the learning tasks, as depicted in Fig. 2. The teacher did give help, feedback and coaching if needed. At the end each student team delivered a plan of action describing a modelling procedure to come to a solution for the modelling issue at hand. At the end of the meeting all students filled in a written questionnaire individually.

In the fourth meeting an evaluative group discussion was held in which students reflected on affective and cognitive aspects in both units. 


\section{Data Collection and Analysis}

Given the purpose of this study, the data required are essentially qualitative. The first two research questions were answered using the group discussion as the primary data source with the written questionnaire as the secondary data source. The delivered plans of action were used as data source for answering the third research question. Below, each data source is described as well as the analysis procedure.

\section{Group Discussion}

The teacher invoked and chaired the discussion. Discussion went on until each point of view was clear and every student was given a chance to give his/her opinion. The framework for the semi-structured group discussion is shown in Table 1. The length of the group discussion was approximately $150 \mathrm{~min}$. The group discussion was audio taped and transcribed verbatim. Next, the discussion was analysed independently by two researchers (first and fourth author of this paper). The analysis was conducted from an interpretative perspective (Smith 1995). Students' statements from the group discussions related to items 1 and 2 were coded according to the criteria of students' interest and ownership. The statements from the group discussion related to item 3 were coded according to familiarity and complexity. These criteria originated from our previous study in which we selected authentic chemical modelling practices suitable as contexts (Prins et al. in press). The inter coder agreement was tested by calculating the percentage of statements coded equally by both researchers. We regarded $80 \%$ as the lower limit for a substantial level of agreement (Miles and Huberman 1994). Next, both researchers analysed all equally coded statements to identify major trends. Finally, all results were discussed in the complete research team.

\section{Written Questionnaire}

Each student filled in a questionnaire for the Treatment and Exposure units. The questionnaire contained items on the students' interest, ownership, familiarity and complexity. The items in the written questionnaire are shown in Table 2. Afterwards all answers of the students were collected and summarized by one researcher (first author). The results were used to validate the findings from the group discussion.

Table 1 Questions to start the semi-structured group discussion

1. Please indicate your willingness to carry out the remaining part of the unit 'Modelling drinking water treatment'? Should we continue with this unit for use in chemistry classes?

2. Please indicate your willingness to carry out the remaining part of the unit 'Modelling human exposure and uptake of chemicals in consumer products'? Should we continue with this unit for use in chemistry classes?

3. In both units you worked with mathematical models developed in real practices. These models as used as predictive tools. With the knowledge you now have about these models, what do you think of the reliability of these models? 
Table 2 Items in individual written questionnaire for students

1. I would like to carry out the remaining part of the unit and solve the problem? Yes $\square$

$$
\text { No } \square
$$

2. Did you ever hear of these kinds of real existing problems before? If yes, what and in what manner?

3. Do you judge the topic studied as interesting I motivating I relevant?

4. Please give your opinion on the difficulty of the unit.

5. Comment on the following statement: In this unit I am able to use own ideas and knowledge.

6. Please indicate what you would like to learn about the employed models?

\section{Plans of Action}

Each student team delivered a plan of action outlining a modelling procedure (learning task 4). All plans of actions were analysed by two researchers independently (first and fourth author of this paper). Preceding the analysis, both researchers developed and agreed upon a reference modelling procedure as evaluative framework. This framework consisted of a description according to the modelling process for general application (Webb 1994) on each unit. The reference modelling procedures were used as instruments to identify modelling stages within the plans of action of the student teams, to match these to one of the conceptual modelling stages and to judge the quality. The sequence of the stages in the plans of action had no evaluative criterion, since many modelling processes proceed iteratively. The reference modelling procedures for each unit are shown in Table 3.

The quality of each modelling stage was judged by comparing the stage description in the plans of action to the corresponding stage description in the reference modelling procedures. The judgements ranged from 1 (low quality) to 5 (high quality). In case a conceptual modelling stage was absent, a zero was noted. A rater consistency check was conducted by calculating the intraclass correlation coefficient using a two-way mixed effects model (Shrout and Fleiss 1979). Afterwards, both researchers discussed differences in quality judgements to identify underlying considerations. Finally, both researchers discussed the plans of action to unravel students' views on the modelling issues. All results were discussed in the complete research team.

\section{Overview Data Sources on Each Research Question}

In Table 4 an overview is given of the data sources used on each research question. In the case of research questions 1 and 2 the group discussion was used as the primary data source, while the written questionnaire was used as the secondary source to validate the findings.

\section{Results}

The enactment of the learning tasks was conducted according to the plan as described in the Method section. All 18 students participated in all four meetings. In this section we present the results for each research question. After every research question the main conclusions will be summarized. 


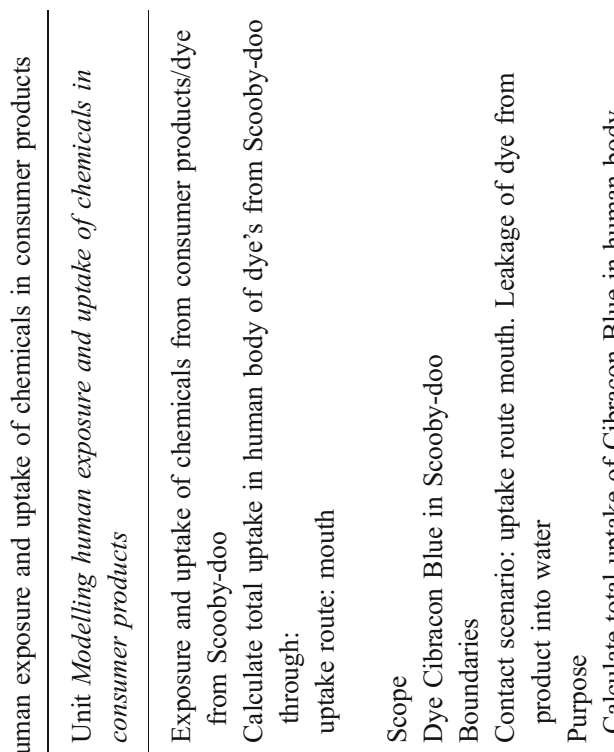

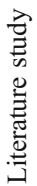
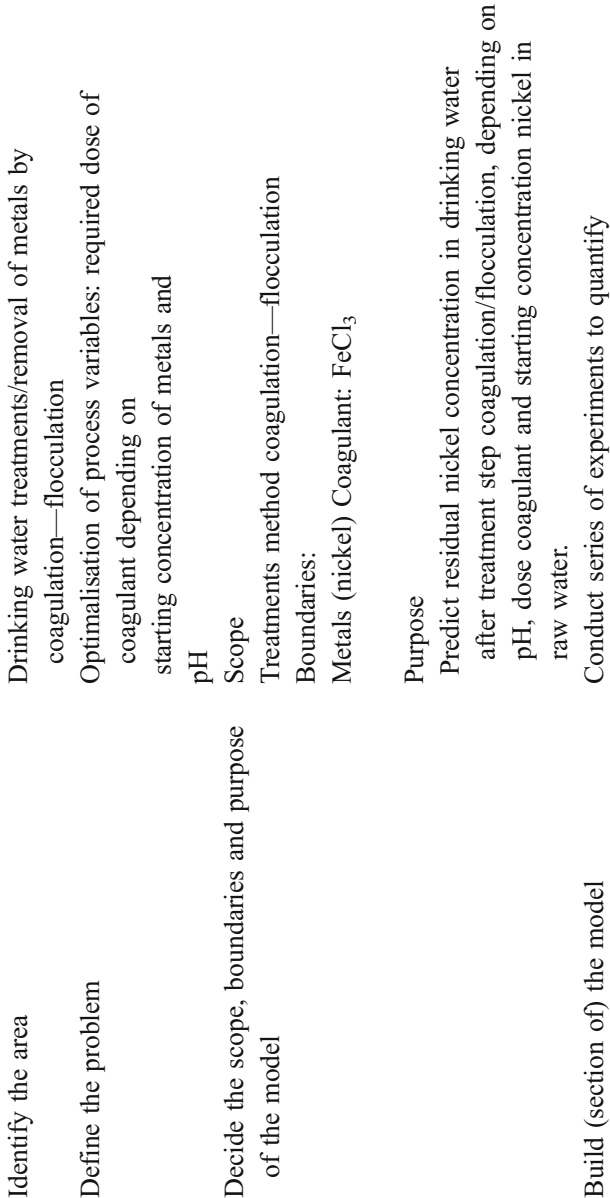

\begin{tabular}{l}
$\overline{0}$ \\
0 \\
0 \\
0 \\
$\Xi$ \\
0 \\
0 \\
0 \\
0 \\
0 \\
0 \\
0 \\
0 \\
\hline 0 \\
\hline 0
\end{tabular} 

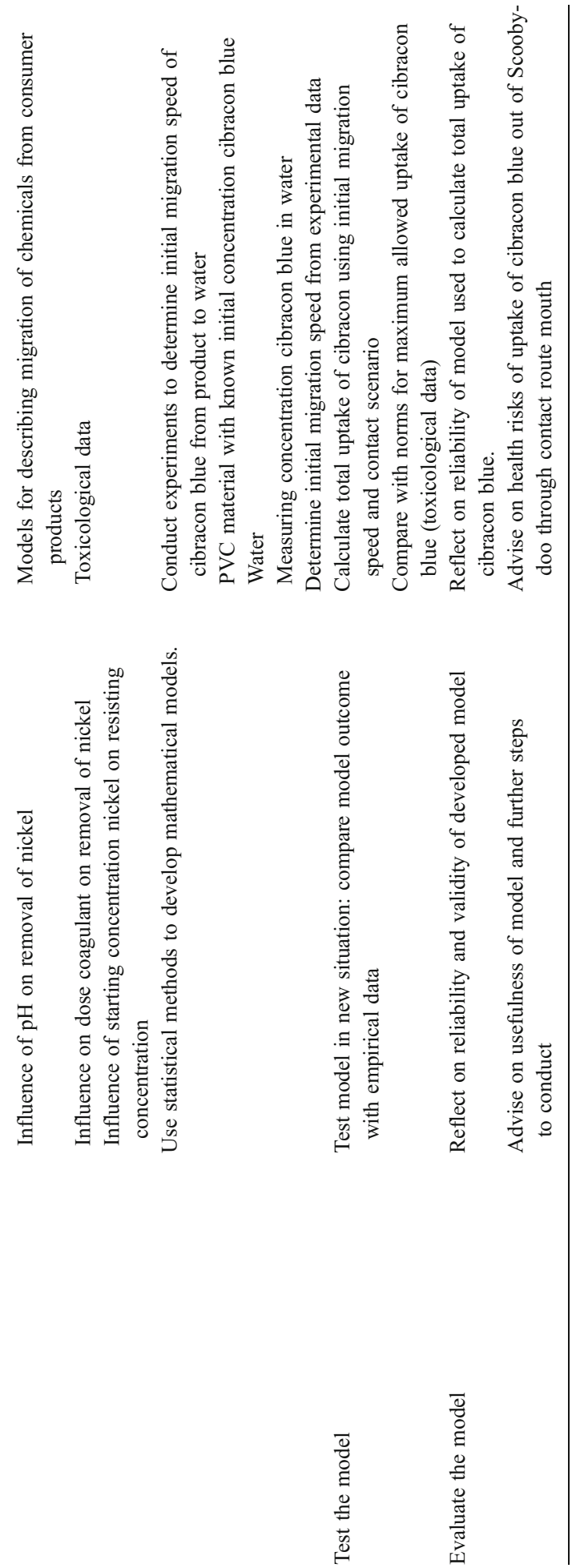
Table 4 An overview of primary and secondary data sources on each research question

\begin{tabular}{|c|c|c|}
\hline Number & Research question & Data sources \\
\hline 1 & $\begin{array}{l}\text { To what extent does the use of authentic practices as } \\
\text { contexts evoke students' interest and initiate ownership? }\end{array}$ & $\begin{array}{l}\text { Primary: group discussion items } 1,2 \\
\text { Secondary: written questionnaire } \\
\text { items } 1,3,5\end{array}$ \\
\hline 2 & $\begin{array}{l}\text { To what extent do the familiarity and complexity of } \\
\text { the modelling issues comply with students' cognitive } \\
\text { abilities? }\end{array}$ & $\begin{array}{l}\text { Primary: group discussion item } 3 \\
\text { Secondary: written questionnaire } \\
\text { items } 2,4,6\end{array}$ \\
\hline 3 & $\begin{array}{l}\text { To what extent are students able to express a rudimentary } \\
\text { procedure in response to a modelling issue, in terms of a } \\
\text { sequence of activities and relevant issue knowledge? }\end{array}$ & Plans of action \\
\hline
\end{tabular}

Research question 1: To what extent does the use of authentic practices as contexts evoke students' interest and initiate ownership?

The group discussion revealed that a majority of the students (14 out of 18) experienced both units as interesting. Students appraised the high level of authenticity, as evidenced by the exemplary comment below.

David $^{1}$ : '... the subject, something useful for yourself ..... in normal chemistry classes, you are busy with formulas and so on, and you think: what am I supposed to do with it? And now it is just a real subject'. (GD) ${ }^{2}$

Also statements emphasising the general value of learning models and modelling were articulated, such as 'models are used in all of science', 'good preparation for my studies later on' and 'really want to understand models'.

Tom: 'You learn about treatment processes .... you are very busy with that [drinking water treatment] .... you have to think of a plan of action yourself .... you really learn to understand the models ..... I liked that very much'. (GD)

As for ownership, the majority of the students appreciated the thinking over experiments to collect empirical data.

Anna: 'Yes, I found it enjoyable that you had to think creatively about how to conduct the experiments .... you have to think about normal water as replacement of real saliva, and how to simulate chewing and sucking'. (GD)

The independent coding revealed a substantial level of agreement in coding (i.e., 85\%). Two major trends were identified within students' interest: 'appreciation of the clear link between chemical theory and practice' and 'the value of understanding models and learning to construct models'. A major trend within ownership was that both units encourage students to think 'creatively about experiments'.

The written questionnaire confirmed these results. Fifteen students were willing to continue with the Treatment unit while 14 students expressed a willingness to continue with

\footnotetext{
${ }^{1}$ All names used in this research study are pseudonyms.

${ }^{2}$ All of the references here are to the specific data source used, where GD stands for Group Discussion.
} 
the Exposure unit. As it comes to ownership, 12 students agreed with the statement that the units promote the use of their own ideas and knowledge.

Judy: 'It is less theoretical [compared to normal chemistry class] and with more emphasis on self investigation. You are able to use own knowledge and ideas'. (WQ) ${ }^{3}$

Only three students were not interested in continuing with the Treatment unit while four students were not interested in the case of the Exposure unit. These students qualified the modelling issues as 'too much mathematics included', 'lack of relevance for personal life' or 'too much overload of new chemistry concepts'. Six students made a reservation regarding ownership, because the units were too much focussed on common sense notions and knowledge, in stead of specific-issue (chemistry) knowledge'.

\section{Research question 2: To what extent are students familiar with the modelling issues and able to manage the complexity?}

Comparison of the independent coding showed a substantial $83 \%$ level of agreement. In general, the results revealed that students were familiar with the chemical concepts involved. In addition, students recognized the major steps in the approach of experts to come to a solution, as typified by students' comments below.

Susan: 'It is more about .... a lot is asked about your own knowledge, general knowledge so to say .... and some things [learning activities] were so obviously logical'. (GD)

Mary: 'Yes, for example the steps engineers take to come to a solution [Modelling drinking water treatment], those are really logical. Of course, first you have to see what is in it followed by what can be improved. Next you have to figure out how and then you come to a conclusion. That is all really logical'. (GD)

However, as it comes to the mathematical models employed the results showed a more dispersed picture. The main trends emerging from the data were that students were rather unfamiliar with the syntax of the formula's, the construction method and the empirical validation of the models. These trends also were reflected in the students' statements about complexity, the origin and determination of the constants, and the number of process variables and constants involved. Furthermore, the application of the models in analogue situations raised difficulties.

Tracy: 'I found it difficult to work with [formula], because of the many constants that are different in other situations, so you have to know exactly what those variables do and how to adjust the formula to fit the other substance'. (GD)

These findings were confirmed by the written questionnaire. The majority of students (i.e., 13 in the Treatment unit and 16 in the Exposure unit) reported that newspapers and television were sources of their familiarity with the issues. In the case of the Treatment unit, students came up with statements such as 'Ground and surface water are polluted with chemical contaminants: problems with purification' and 'Process of water treatment: complex with many different steps'. As for the Exposure unit, statements were mentioned like 'Kids toys, e.g. Scooby doo ropes, contain hazardous contaminants that are released' and 'Consumer products might contain hazardous chemicals'. In both units students indicated that they would like to learn about 'method to construct these kinds of models' and 'investigate all the variables included in the models'.

\footnotetext{
${ }^{3}$ All of the references here are to the specific data source used, where WQ stands for Written Questionnaire.
} 
Based on these findings, we concluded that students were challenged to extend their knowledge. Students showed willingness for self construction of the models, nevertheless their unfamiliarity with the models. The experienced complexity was mainly focused on the amount of variables and constants, the origin and determination of the constants and the usability of the models in analogue situations.

Research question 3: To what extent are students able to express a rudimentary procedure in response to modelling issues, in terms of a sequence of activities accompanied by relevant issue knowledge?

The analysis of the student teams' plans of action focused on the completeness and quality of the modelling procedures. We first describe the results in the Treatment unit. In Table 5 an overview is presented of the stages present in the delivered plans of action in the unit as well as their quality.

The judgement showed a substantial consistency between the raters reflected in the intraclass correlation coefficient of 0.88 . To exemplify differences in judging and give insight into the underlying considerations, we reflect on the stage 'build (a section of) the model' for team III. The actual stage description was:

Team III defined the build (a section of) the model as: 'Process variables: dose [coagulant], stirring intensity and residual time. The $\mathrm{pH}$ : determine the optimal $\mathrm{pH}$ value by conducting experiments. The $\mathrm{Fe}^{3+}$ can only work if it stays strongly charged. If the $\mathrm{pH}$ would turn alkaline, the $\mathrm{Fe}^{3+}$ would turn less charged. The $\mathrm{pH}$ should be neutral, we think. That is our $\mathrm{pH}$ hypothesis. The $\mathrm{ABC}$ values [fit parameters] will be differently [compared to analogue problem]. We determine the $\mathrm{ABC}$ values by fitting. After investigation and with experimental results we are able to determine the $\mathrm{ABC}$ and develop a formula.'

Researcher 1 judged the quality as very low, because no explicit reference was made to investigating the correlations between process variables and residual nickel concentration after coagulation/flocculation treatment. On the contrary, researcher 2 valued the fact that all process variables were mentioned, the arguments on the possible influence of the $\mathrm{pH}$ and the notion of 'fitting as means to calibrate a model to serve a new situation'.

Table 5 Overview of the results of the analysis procedure conducted by two researchers independently of the plans of action in unit Modelling drinking water treatment

\begin{tabular}{|c|c|c|c|c|c|c|c|c|c|c|c|c|}
\hline \multirow{3}{*}{ Stages in modelling procedure ${ }^{a}$} & \multicolumn{12}{|c|}{ Team $^{\mathrm{b}}$} \\
\hline & \multicolumn{2}{|l|}{$\mathrm{I}$} & \multicolumn{2}{|l|}{ II } & \multicolumn{2}{|l|}{ III } & \multicolumn{2}{|l|}{ IV } & \multicolumn{2}{|l|}{$\mathrm{V}$} & \multicolumn{2}{|l|}{ VI } \\
\hline & R1 & $\mathrm{R} 2$ & R1 & $\mathrm{R} 2$ & R1 & $\mathrm{R} 2$ & $\mathrm{R} 1$ & $\mathrm{R} 2$ & R1 & $\mathrm{R} 2$ & R1 & $\mathrm{R} 2$ \\
\hline Identify the area & 5 & 5 & 5 & 5 & 5 & 5 & 5 & 5 & 5 & 5 & 5 & 5 \\
\hline Define the problem & 4 & 3 & 4 & 5 & 5 & 4 & 4 & 5 & 4 & 1 & 5 & 5 \\
\hline $\begin{array}{l}\text { Decide the scope, boundaries and } \\
\text { purpose of the model }\end{array}$ & 4 & 5 & 3 & 5 & 3 & 5 & 4 & 5 & 4 & 3 & 4 & 5 \\
\hline Build (a section of) the model & 4 & 3 & 4 & 5 & 1 & 5 & 4 & 5 & 4 & 2 & 4 & 5 \\
\hline Test the model & 5 & 5 & 1 & 4 & 2 & 2 & 1 & 4 & 0 & 0 & 0 & 0 \\
\hline Evaluate the model & 5 & 3 & 0 & 0 & 2 & 2 & 1 & 3 & 5 & 1 & 2 & 2 \\
\hline
\end{tabular}

\footnotetext{
${ }^{\text {a }}$ Conceptual modelling stages expected to be present and described in the plans of action of student teams.

${ }^{\mathrm{b}}$ The judgement results per stage in each plan of action per team. R1 refers to the first researcher, R2 to the second. 0 Stage not present, no quality judgement possible, 1 very low quality, 2 low quality, 3 medium quality, 4 high quality, 5 very high quality
} 
Hereafter we reflect on students' views on the modelling issue by summarizing exemplary stages rated with a high quality. All student teams mentioned 'drinking water treatment' and treatment step 'coagulation/flocculation' as problem area (stage 1). In addition, four teams had clear sight of the problem, as illustrated by the citation below from the plan of action of student team IV:

Team IV defined the problem as: ' $\ldots$.calculate the optimal value for each process variables, by varying one at the time while keeping the others constant.'

The second and third stages were all present with sufficient quality. All teams focused on the 'removal of nickel' during coagulation/flocculation using 'coagulant $\mathrm{FeCl}_{3}$ '. Student team II described the building of the model (stage 4) in much detail, as typified by the citation below:

Team II defined the building of (a section of) the model as: 'We propose the following experiments to find a correlation. We measure the correlation between the starting concentration of heavy metals and the outgoing concentration of heavy metals. This variable we call $\mathrm{A}$. We measure the correlation between the dose of the coagulant and the final concentration of heavy metals. This variable we call B. We measure the correlation between the $p H$ and the final concentration of heavy metals. This variable we call C. [cont'd]. We do a series of small experiments to discover the correlations. After this we develop a good formula, and conduct extensive experiments.'

However, starting from the fifth stage, the testing of the model, the quality decreased. Only student team I described stages 5 and 6 with sufficient quality.

Team I defined the testing of the model as: 'Develop a formula on small scale [by performing laboratory experiments] and evaluate this [formula] in practice.'

Team I defined the evaluation of the model as: 'Discuss [the results]. Check the hypothesis, the conditions and reliability [of the model].'

Table 6 Overview of the results of the analysis procedure conducted by two researchers independently of the plans of action in unit Modelling human exposure and uptake of chemicals in consumer products

\begin{tabular}{|c|c|c|c|c|c|c|c|c|c|c|c|c|}
\hline \multirow[t]{3}{*}{ Stages in modelling procedure ${ }^{\mathrm{a}}$} & \multicolumn{12}{|c|}{ Team $^{\mathrm{b}}$} \\
\hline & \multicolumn{2}{|l|}{ I } & \multicolumn{2}{|l|}{ II } & \multicolumn{2}{|l|}{ III } & \multicolumn{2}{|l|}{ IV } & \multicolumn{2}{|l|}{ V } & \multicolumn{2}{|l|}{ VI } \\
\hline & R1 & $\mathrm{R} 2$ & $\mathrm{R} 1$ & $\mathrm{R} 2$ & R1 & $\mathrm{R} 2$ & $\mathrm{R} 1$ & $\mathrm{R} 2$ & $\mathrm{R} 1$ & $\mathrm{R} 2$ & R1 & $\mathrm{R} 2$ \\
\hline Identify the area & 5 & 5 & 5 & 5 & 5 & 5 & 5 & 5 & 5 & 5 & 3 & 3 \\
\hline Define the problem & 5 & 4 & 5 & 5 & 5 & 3 & 4 & 3 & 5 & 5 & 3 & 3 \\
\hline $\begin{array}{l}\text { Decide the scope, boundaries and } \\
\text { purpose of the model }\end{array}$ & 4 & 5 & 5 & 5 & 4 & 4 & 4 & 3 & 5 & 5 & 2 & 3 \\
\hline Build (a section of) the model & 4 & 5 & 3 & 4 & 4 & 4 & 4 & 4 & 4 & 4 & 4 & 4 \\
\hline Test the model & 4 & 4 & 4 & 4 & 0 & 0 & 4 & 2 & 5 & 4 & 4 & 4 \\
\hline Evaluate the model & 4 & 5 & 3 & 5 & 0 & 0 & 3 & 4 & 4 & 5 & 3 & 3 \\
\hline
\end{tabular}

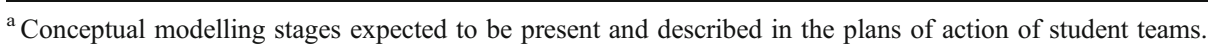

b The judgement results per stage in each plan of action per team. R1 refers to the first researcher, R2 to the second.

0 stage not present, no quality judgement possible, 1 very low quality, 2 low quality, 3 medium quality, 4 high quality, 5 very high quality 
We now turn to the unit Exposure. In Table 6 the results for the unit Exposure are shown.

The inter-rater consistency was sufficient (i.e., $r=0.71$ ). To exemplify differences in rating, we reflect on the stage 'test the model' of team IV.

Team IV defined the test the model as: 'Check the existing formulas by filling in data.

If not, use the data to develop a new formula. Calculate the average value [uptake]

with use of the developed formula and toxicological data. Evaluate the risks."

Researcher 1 judged the quality as high, since explicit reference was made to data from 'external sources', such as experiments and toxicological data. However, researcher 2 rated low quality, because the contact scenario was only mentioned implicitly. Besides, the uptake was not differentiated to the type of consumer, such as children or adults.

All teams had clear sight on the area and the exemplary problem, as typified by citations like 'exposure to chemicals/dyes from Scooby-doo ropes' and 'calculate the total uptake of cibracon'. All teams explicitly described the contact scenario, part of the third modelling stage, as typified below:

Team I defined the decision on the scope, boundaries and purpose of the model as: 'Determine the contact scenario: determine the weight, duration of the contact and contact surface in the mouth.'

The results revealed that the student teams had a clear sight on modelling activities to perform in the fourth stage, building (a section of) the model. Team III described the fourth stage as follows:

Team III defined the decision on the scope, boundaries and purpose of the model as: '... about dyes much data is available. From this data one is able to calculate the upper limit for uptake in milligram per kilogram body weight without any running into health risks [toxicological data]. The contact scenario is the same [mouth], but the initial leakage rate $\mathrm{R}$ is different. We first determine how much gram of dyes is in 100 gram of Scooby-doo rope (...). We determine the volume and surface of that 100 gram of Scooby-doo rope. We use real human saliva instead of water, to determine the uptake of dyes. We do plot the data in a diagram (...).'

In addition, four teams extensively described the experimental setup, all focused on measuring the initial leakage rate. In the final stages, although on average less in quality than the first four stages, five teams explicitly mentioned that the calculated total uptake must be compared with the legally set maximum allowed uptake. We present two exemplary descriptions of stages test the model and evaluate the model:

Team V defined the testing of the model as: ' $\ldots$ with the model and the contact scenario one can calculate the uptake. This total uptake should be compared to the norm, revealing a conclusion ....'

Team II defined the evaluation of the model as: ‘... draw conclusions and relate to data and norm. The exact conclusion has to be based on the results. We have to point out whether potential harmful or not ....'

The findings from the Treatment and Exposure units suggest that student teams were well able to articulate a modelling procedure. They showed that students coupled modelling activities with relevant issue knowledge, while constantly having the purpose of the modelling in mind. Another aspect emerging from the data was the difference in quality 
between the first four modelling stages and the last two. Apparently, the student teams had a clear sight on the modelling actions to perform until the testing and evaluation of the model.

\section{Conclusions and Discussion}

This study has evaluated students' involvement in modelling processes using authentic practices as contexts. The results reveal that students were interested in both units. Most of the students appreciated the approach, the authenticity of the modelling issues and the challenges to devise a solution themselves. As it comes to ownership, the results indicate that both units potentially allow students to act relatively autonomously. In short, both units meet condition A to a large extent. As for the cognitive domain, it can be concluded that students were sufficiently familiar with the chemical concepts involved. However, students were unfamiliar with the employed mathematical models. In addition, the amount of variables involved and unknown origin of the constants raised the complexity. Despite this unfamiliarity with the models and perceived complexity, there were enough indications that students were able to cope with the cognitive load. We concluded that both units do fulfil condition B sufficiently. This conclusion on the cognitive domain is supported by the completeness and quality of the expressed modelling procedures by the student teams (condition C). A noticeable aspect was that the final modelling stages, the testing and evaluation of the model, were of less quality than the preceding stages. Students were aware of the fact that the models had to be tested and evaluated, but they were not able to give content for these stages. In retrospect, it is not surprising since these stages are relevant later on in the modelling (and learning) process, so probably were, at the time, beyond the students' capacity. When (in a subsequent study) a complete curriculum unit is designed, in which students' gradually proceed through the full modelling process, one should account for supplying, in time, students with necessary tools and resources for model testing and evaluation. Despite the lower quality of the final modelling stages, these two units also meet condition $\mathrm{C}$ to a sufficient extent.

The results suggest that authentic practices as context might benefit students' learning of models and modelling. By starting with an orientation on authentic modelling practices, students are provided with a broad route about 'where to go' and 'points to consider'. Furthermore, it facilitates students to connect modelling activities with relevant issue knowledge. In our opinion, the latter is conditional to achieve adequate student involvement in modelling processes. However, the results obtained in this study are subject to limitations. Firstly, it should be noted that these authentic practices were selected after a thorough analysis and judgement (Prins et al., in press). Whether the results can be generalised to other authentic practices, in other science domains, is subject for further study. Secondly, the realized involvement is partly due to adequately designed learning tasks (Fig. 2). The first learning tasks were directed towards an orientation by means of items reporting about societal issues. Two items reported about the issues and one item pointed towards an approach followed in practice to come to a solution. Apparently, such an orientation did evoke students' interest, contributed to perceived relevance and provided students a view to a solution. In our opinion, these three aspects contributed as well to the students' ownership. It thus seems relevant in the introduction phase to articulate to students not only the actuality and relevance of the issue, but also to mention the route to a solution. The final learning task compromised the drawing up of a plan of action to solve an exemplary problem themselves. This open task was facilitated by delivering an already solved analogous problem belonging to the same authentic practice. The analogous problem provided students with the necessary guidelines while 
providing them with opportunities to introduce their own ideas and thoughts. Such a learning task, fostering students to think of a sequence of modelling actions to conduct, proved to be successful. This learning task offers an instrument to enable students to look ahead, which is important for effective engagement in modelling processes. Thirdly, the enactment has taken place outside the classroom. Although the sample of participants might be considered as a fair reflection of an average population of high school chemistry class (grades 10,11), one needs to account for different circumstances. The fourth limitation relates to the teacher preparation. Proper preparation of the teacher is critical. The use of models and the outlining of the unit will be different from what happens in traditional chemistry classes. In the present study the teacher (second author) was engaged in developing the learning tasks. The teacher therefore was well informed with the content and pedagogy of both units.

In conclusion, these two authentic modelling practices might indeed serve as appropriate contexts for involving students in a modelling process. The next steps in this research will be to focus on design strategies for complete curriculum units, based on these authentic practices, followed by testing and evaluation in classrooms. The design of complete curriculum units will be conducted in close cooperation with teachers. The challenge is to design a sequence of the learning tasks such that students do see the point of what they are doing at every step in the unit (Klaassen and Lijnse 2004). To achieve such a sequence of learning tasks, the activity pattern of the experts in the authentic practice provides heuristic guidelines. At the end of such units we need to design learning activities to induce reflection of students' modelling process. During such reflection activities students should learn about essential model characteristics, like purpose, boundaries and limitations, reliability and validity.

Many research studies have been conducted on students' understanding of models and modelling. In general they call for greater emphasis on the role and purpose of models in science. In the present study an effort has been made to contribute to the knowledge about this emphasis. Meaningful learning of models and modelling requires a context in which modelling activities and issue knowledge are closely related. Such coherency might be realised by using authentic chemical modelling practices as sources of inspiration. The results obtained in this study so far confirmed this hypothesis. In subsequent studies we aim to further contribute to the development and elaboration of design knowledge for adapting authentic practices into curriculum units to construct meaningful learning trajectories.

Acknowledgements The authors wish to thank the 18 students from the three schools in Utrecht, Bonifatius College, Werkplaats Kindergemeenschap and Christelijk Gymnasium Utrecht, and their teachers for their participation and their contribution to this research study.

Open Access This article is distributed under the terms of the Creative Commons Attribution Noncommercial License which permits any noncommercial use, distribution, and reproduction in any medium, provided the original author(s) and source are credited.

\section{References}

Bennett, J., \& Holman, J. (2002). Context-based approaches to the teaching of chemistry: what are they and what are their effects? In J. K. Gilbert, O. De Jong, R. Justi, D. F. Treagust, \& J. H. Van Driel (Eds.), Chemical Education: Towards Research-based practice (pp. 165-184). Dordrecht: Kluwer Academic.

Buckley, B. C. (2000). Interactive multimedia and model-based learning in biology. International Journal of Science Education, 22(9), 895-935. doi:10.1080/095006900416848. 
Bulte, A. M. W., Klaassen, K., Westbroek, H. B., Stolk, M. J., Prins, G. T., Genseberger, R., et al. (2005). Modules for a new chemistry curriculum, research on a meaningful relation between contexts and concepts. In P. Nentwig, \& D. Waddington (Eds.), Context based learning of science (pp. 273-299). Münster: Waxmann.

Bulte, A. M. W., Westbroek, H. B., De Jong, O., \& Pilot, A. (2006). A research approach to designing chemistry education using authentic practices as contexts. International Journal of Science Education, 28(9), 1063-1086. doi:10.1080/09500690600702520.

Carey, S. (1985). Are children fundamentally different kinds of thinkers than adults. In S. F., Chipman, J. W., Segal, R., \& Glaser (Eds.), Thinking and Learning Skills (vol. 2, pp. 485-517). Hillsdale: Erlbaum.

Carr, M. (1984). Model confusion in chemistry. Research in Science Education, 14, 97-103. doi:10.1007/ BF02356795.

Clement, J. (2000). Model based learning as a key research area for science education. International Journal of Science Education, 22, 1041-1053. doi:10.1080/095006900416901.

Cobb, P., Stephan, M., McClain, K., \& Gravemeijer, K. (2001). Participating in classroom mathematical practices. The Journal of the Learning Sciences, 10(1\&2), 113-163. doi:10.1207/S15327809JLS10-1-2_6.

Edelson, D. C. (1998). Realising authentic science learning through the adaptation of scientific practice. In B. J. Fraser, \& K. G. Tobin (Eds.), International Handbook of Science Education (vol. I, pp. 317-331). Dordrecht: Kluwer.

Erduran, S., \& Duschl, R. A. (2004). Interdisciplinary characterizations of models and the nature of chemical knowledge in the classroom. Studies in Science Education, 40, 105-138. doi:10.1080/ 03057260408560204.

Gilbert, J. K. (2004). Models and modelling: routes to more authentic science education. International Journal of Science and Mathematics Education, 2, 115-130. doi:10.1007/s10763-004-3186-4.

Gilbert, J. K. (2006). On the nature of "context" in chemistry education. International Journal of Science Education, 28(9), 957-976. doi:10.1080/09500690600702470.

Gilbert, J. K., \& Boulter, C. J. (2000). Developing Models in Science Education. Dordrecht: Kluwer Academic.

Grosslight, L., Unger, C., Jay, E., \& Smith, C. (1991). Understanding models and their use in science: conceptions of middle and high school students and experts. Journal of Research in Science Teaching, 28(9), 799-822. doi:10.1002/tea.3660280907.

Harrison, A. G., \& Treagust, D. F. (1996). Secondary students' mental models of atoms and molecules: implications for teaching science. Science Education, 80(5), 509-534. doi:10.1002/(SICI)1098-237X (199609)80:5<509::AID-SCE2>3.0.CO;2-F.

Harrison, A. G., \& Treagust, D. F. (1998). Modelling in science lessons: are there better ways to learn with models? School Science and Mathematics, 98(8), 20-42.

Harrison, A. G., \& Treagust, D. F. (2000). A typology of school science models. International Journal of Science Education, 22(9), 1011-1026. doi:10.1080/095006900416884.

Hodgson, T. (1995). Secondary mathematics modeling: issues and challenges. School Science and Mathematics, 95, 351-358.

Hogan, K., \& Thomas, D. (2001). Cognitive comparisons of students' systems modelling in ecology. Journal of Science Education and Technology, 10(4), 319-345. doi:10.1023/A:1012243102249.

Ingham, A. M., \& Gilbert, J. K. (1991). The use of analogue models by students of chemistry at higher education level. International Journal of Science Education, 13, 193-202. doi:10.1080/0950069910130206.

Klaassen, K., \& Lijnse, P. (2004). Didactical structures as an outcome of research on teaching-learning sequences? International Journal of Science Education, 26(5), 537-554. doi:10.1080/ 09500690310001614753 .

Leont'ev, A. N. (1978). Activity, Consciousness and Personality. Englewood Cliffs: Prentice-Hall.

Lijnse, P. L. (1995). 'Developmental Research' as a way to empirically based 'Didactical Structure of Science'. Science Education, 79(2), 189-199. doi:10.1002/sce.3730790205.

Linn, M. C., Songer, N. B., \& Lewis, E. L. (1991). Overview: Students' models and epistemologies of science. Journal of Research in Science Teaching, 28, 729-732. doi:10.1002/tea.3660280903.

Miles, M. B., \& Huberman, A. M. (1994). Qualitative data analysis: a sourcebook of new methods (2nd ed.). Thousand Oaks: Sage.

Penner, D. E., Lehrer, R., \& Schauble, L. (1998). From physical models to biomechanics: a design-based modeling approach. The Journal of the Learning Sciences, 7(3-4), 429-449. doi:10.1207/ s15327809j1s0703\&4_6.

Prins, G. T., Bulte, A. M. W., Van Driel, J. H., \& Pilot A. (in press). Selection of authentic modelling practices as contexts for chemistry education. International Journal of Science Education. doi:10.1080/ 09500690701581823 .

Raghavan, K., \& Glaser, R. (1995). Model-Based Analysis and Reasoning in Science: The MARS Curriculum. Science Education, 79(1), 37-61. doi:10.1002/sce.3730790104. 
Riley, D. (1990). Learning about systems by making models. Computers and Education, 15(1-3), $255-263$. doi:10.1016/0360-1315(90)90155-Z.

Roth, W.-M. (1998). Designing communities. Dordrecht: Kluwer Academic.

Sadler, T. D. (2007). The aims of science education: unifying the fundamental and derived senses of scientific literacy. Paper presented at the Linnaeus symposium on Promoting scientific literacy, Uppsala, Sweden.

Shrout, P. E., \& Fleiss, J. L. (1979). Intraclass correlations: Uses in assessing rater reliability. Psychological Bulletin, 86(2), 420-428. doi:10.1037/0033-2909.86.2.420.

Smith, J. A. (1995). Semi-structured interviewing and qualitative analysis. In J. A. Smith, R. Harre, \& L. Van Langenhove (Eds.), Rethinking Methods in Psychology. (pp. 9-26). Thousand Oaks: Sage.

Taconis, R., Ferguson-Hessler, M. G. M., \& Broekkamp, H. (2001). Teaching science problem solving: an overview of experimental work. Journal of Research in Science Teaching, 38(4), 442-468. doi:10.1002/ tea. 1013.

Van der Valk, T., Van Driel, J. H., \& De Vos, W. (2007). Common characteristics of models in present-day scientific practice. Research in Science Education, 37, 469-488. doi:10.1007/s11165-006-9036-3.

Vygotsky, L. S. (1978). Mind in society. The development of higher psychological processes. Cambridge: Harvard University Press.

Webb, M. E. (1994). Beginning computer-based modelling in primary schools. Computers in Education, 22 (1), 129-144. doi:10.1016/0360-1315(94)90081-7.

Westbroek, H. B. (2005). Characteristics of Meaningful Chemistry Education. Utrecht: CD-ß. 